\title{
Treatment of osteochondral lesions of the talus: a systematic review
}

\author{
Maartje Zengerink $\cdot$ Peter A. A. Struijs • \\ Johannes L. Tol · Cornelis Niek van Dijk
}

Received: 4 June 2009/Accepted: 14 September 2009/Published online: 27 October 2009

(c) The Author(s) 2009. This article is published with open access at Springerlink.com

\begin{abstract}
The aim of this study was to summarize all eligible studies to compare the effectiveness of treatment strategies for osteochondral defects (OCD) of the talus. Electronic databases from January 1966 to December 2006 were systematically screened. The proportion of the patient population treated successfully was noted, and percentages were calculated. For each treatment strategy, study size weighted success rates were calculated. Fifty-two studies described the results of 65 treatment groups of treatment strategies for OCD of the talus. One randomized clinical trial was identified. Seven studies described the results of non-operative treatment, 4 of excision, 13 of excision and curettage, 18 of excision, curettage and bone marrow stimulation (BMS), 4 of an autogenous bone graft, 2 of transmalleolar drilling (TMD), 9 of osteochondral transplantation (OATS), 4 of autologous chondrocyte implantation (ACI), 3 of retrograde drilling and 1 of fixation. OATS, BMS and ACI scored success rates of 87,85 and $76 \%$, respectively. Retrograde drilling and fixation scored
\end{abstract}

M. Zengerink $(\bowtie) \cdot$ P. A. A. Struijs · C. N. van Dijk

Department of Orthopaedic Surgery, Academic Medical Centre, University of Amsterdam, P.O. Box 22660,

1100 DD Amsterdam, The Netherlands

e-mail: m.zengerink@amc.uva.nl

P. A. A. Struijs

e-mail: p.a.struijs@amc.uva.nl

C. N. van Dijk

e-mail: c.n.vandijk@amc.uva.nl

\section{J. L. Tol}

Sports Medicine Department,

The Hague Medical Centre Antoniushove,

P.O. Box 411, 2260 AK Leidschendam,

The Netherlands

e-mail: h.tol@mchaaglanden.nl
88 and $89 \%$, respectively. Together with the newer techniques OATS and ACI, BMS was identified as an effective treatment strategy for OCD of the talus. Because of the relatively high cost of ACI and the knee morbidity seen in OATS, we conclude that BMS is the treatment of choice for primary osteochondral talar lesions. However, due to great diversity in the articles and variability in treatment results, no definitive conclusions can be drawn. Further sufficiently powered, randomized clinical trials with uniform methodology and validated outcome measures should be initiated to compare the outcome of surgical strategies for OCD of the talus.

Keywords Ankle - Osteochondral lesion - Defect . Talus $\cdot$ Systematic review $\cdot$ Arthroscopy

\section{Introduction}

Symptomatic osteochondral ankle defects often require surgical treatment. An osteochondral ankle defect is a lesion of the talar cartilage and subchondral bone mostly caused by a single or multiple traumatic events, leading to partial or complete detachment of the fragment. The defects cause deep ankle pain associated with weightbearing. Impaired function, limited range of motion, stiffness, catching, locking and swelling may be present. These symptoms place the ability to walk, work and perform sports at risk.

The injury was classified by Berndt and Harty in 1959 [6]. Anatomic studies on cadaver limbs demonstrated the etiological mechanism of transchondral fractures of the lateral border of the talar dome. As the foot is inverted on the leg, the lateral border is compressed against the face of the fibula (stage I), while the collateral ligament remains intact. Further inversion ruptures the lateral ligament and 
begins avulsion of the chip (stage II), which may be completely detached but remain in place (stage III) or be displaced by inversion (stage IV). Berndt and Harty experimentally proved the traumatic etiology of the lesion; however, non-traumatic lesions also occur.

Treatment strategies for osteochondral defects (OCDs) of the ankle have substantially increased over the last decade. The widely published treatment strategies of symptomatic osteochondral lesions include the non-surgical treatment with rest or cast immobilization, and surgical excision of the lesion, excision and curettage, excision combined with curettage and drilling/microfracturing (i.e., bone marrow stimulation, BMS), placement of an autogenous (cancellous) bone graft, antegrade (transmalleolar) drilling (TMD), retrograde drilling, fixation and newer techniques like osteochondral transplantation (osteochondral autograft transfer system, OATS) and autologous chondrocyte implantation (ACI). The last two techniques focus at replacement and regeneration of hyaline cartilage, respectively.

The goal of these treatment strategies is to diminish symptoms like pain and swelling, and to improve function. Publications on the effectiveness of these treatment strategies vary. In most cases, several treatment options are viable, and the choice of treatment is based on the type and size of the defect and on preferences of the treating clinician.

The last systematic review concerning treatment strategies for OCDs of the talar dome was an update of a previous review [57] and included studies up to June 2000 [61]. However, since this date many studies concerning the newer techniques ACI [4, 16, 40, 63] and OATS have been published [1, 15, 17, 20, 28, 31, 47, 49, 50]. The aim of this study is to provide an up to date overview by pooling those studies dealing with treatment strategies for osteochondral ankle defects in order to summarize the effectiveness of these strategies.

\section{Patients and methods}

Electronic databases MEDLINE, EMBASE, CENTRAL and DARE (January 1966-December 2006) were screened. As main key words 'Therapy; Treat*; Talus; Talar; Ankle; Cartilage*; Osteochondritis Dissecans; Chondral; Osteochondral and Transchondral were used. The search strategy for MEDLINE was as follows: (therapy or treat\$) and (talar or talus or ankle) and (cartilag\$ or osteochondritis dissecans or talar or chondral or osteochondral or transchondral). No language limitations were imposed. The reference lists of all the articles selected were screened for additional articles.

All RCTs or quasi-experimental research that evaluated the effectiveness of treatment strategies for osteochondral lesions of the talus were included. This included case series. Published studies describing the results of the following treatment strategies were included: non-operative treatment-rest, non-operative treatment - cast, excision of the fragment, excision and curettage, excision and curettage and drilling/microfracturing, placement of a cancellous bone graft, antegrade (transmalleolar) drilling, OATS, ACI, retrograde drilling and fixation of the lesion. Studies/ patients were excluded if: a combination of diagnoses was evaluated, and results were not separately described for the osteochondral talar lesion group, follow-up was less than 6 months, therapy was inadequately described, patients were under 18 years old, less than 10 patients were included (excluding single case reports), the study was the lesser extensive of a double publication, there was no welldefined outcome and if there was a combination of therapies described, and results were not described per therapy. Two reviewers (MZ and DO) independently assessed the articles for inclusion. Forms specifically developed for and tailored to this review were used. Agreement was needed for inclusion. In case of disagreement, the opinion of a third independent investigator (CvD) was decisive. To prevent investigator bias, scoring of the manuscript was blinded to author and institute.

Successful treatment was defined as an excellent or good result at follow-up, defined by an accepted scoring system, like the AOFAS Ankle/Hindfoot scale [24], the Hannover Scoring System [54] and others (see Table 2). If the success rate was not defined by the author, the results were integrated into the widely accepted scoring system of Thompson and Loomer [56]. The proportion of the patient population treated successfully was noted, and percentages were calculated. For each treatment strategy, study size weighted success rates were calculated (for each treatment category: sum of the successfully treated patients divided by the total number of treated patients within that category).

The primary outcomes were the effects of treatment on symptoms, measured by scoring systems concerning the ankle (mainly the AOFAS Ankle/Hindfoot scale).

The Newcastle-Ottawa Scale (NOS) [62], adjusted for case series, was used for quality assessment of the included studies. It was originally developed as an instrument to provide an easy and convenient tool for quality assessment of nonrandomized studies, i.e., case-control and cohort studies, to be used in a systematic review. The NewcastleOttawa Scale uses a "star" rating system to judge quality based on three aspects of the study: selection of study groups, comparability of study groups and ascertainment of either the exposure or outcome of interest (dependent on assessment of case-control or cohort study, respectively). The maximum number of stars a study may receive in each of these three categories is 4,1 and 3 , respectively, for a 
total of 8 possible stars. The validity of the scale has been previously established. In orthopedic literature, the vast majority of publications involve case series. We adjusted the NOS for case series to perform a quality assessment of the included case series. Studies were scored for study design, selection and assessment of outcome. The maximum numbers of stars a study could receive in the NOS adjusted for case series was 2, 1 and 2, respectively, for a total of 5 possible stars (Appendix 1).

\section{Results}

Description of studies

The search strategy identified over 2,000 articles. A total of 183 publications describing the results of treatment of talar osteochondral lesions could be identified. One randomized clinical trial was found [17]. Therefore, the conventional measures of summarizing estimates of effectiveness could not be used. We used pooling of the estimates of the outcome in individual studies.

Hundred and thirty-one studies were excluded due to one or more exclusion criteria, being: combination of diagnoses $(n=14)$, inappropriate duration of follow-up $(n=14)$, improper description of therapy $(n=8)$, age under 18 years $(n=17)$, case report $(n=33)$, double publication $(n=17)$, non-interpretable results $(n=37)$, less than 10 patients $(n=37)$ and a combination of therapies $(n=25)$ (Table 1$)$. This left 52 studies describing the results of 65 treatment groups. Three described the results of non-operative treatment-rest, 4 of non-operative treatment-cast, 4 of excision, 13 of excision and curettage, 18 of excision and curettage and BMS, 3 of retrograde drilling, 4 of ACI, 9 of OATS, 1 of fixation with bone pegs, 4 of cancellous bone grafting and 2 of antegrade (transmalleolar) drilling.

Table 1 Criteria that were used

\begin{tabular}{lr}
\hline Exclusion criteria & No. \\
\hline Combination of diagnoses & 14 \\
Follow-up $<6$ months & 14 \\
Therapy inadequately described & 8 \\
$<18$ Years old & 17 \\
Single case report & 33 \\
Double publication & 17 \\
No well-defined outcome & 37 \\
$<10$ Patients & 37 \\
Combination of therapies & 25 \\
Total no. of excluded studies & 202 \\
\hline
\end{tabular}

Population characteristics

The total number of included patients with osteochondral talar lesions in the 52 studies was 1361. The average age was 31 years [18-75], 63\% were male and $37 \%$ female. The right ankle was involved in $57 \%$, the left in $43 \%$. Lesions were medial in $62 \%$, lateral in $36 \%$, central in $1 \%$ and medial and lateral in $1 \%$. A history of ankle trauma was reported in $86 \%$ of cases. There was a primary defect in $84 \%$. For about half of the patients, the Berndt and Harty stage was mentioned. In $13 \%$, it considered a Berndt and Harty stage 1 lesion, in $22 \%$ a stage 2 lesion, in $40 \%$ a stage 3 lesion and in $25 \%$ a stage 4 lesion. The AOFAS Ankle/Hindfoot scale was most used [24] (Table 2).

Treatment strategies

\section{Non-operative treatment: rest}

This may be rest and/or restriction of (sporting) activities with or without treatment of non-steroidal anti-inflammatory drugs (NSAIDs). The aim is to unload the damaged cartilage, so edema can resolve and necrosis is prevented. Another objective could be healing of a (partly) detached fragment to the surrounding bone. Three studies, 86 patients in total, described the results of rest for OCD [7, $45,51]$. Reasons to choose for non-operative treatment were not always clearly described. Two studies date from

Table 2 Scoring systems used for treatment of talar osteochondral lesions in the included studies

\begin{tabular}{ll}
\hline Scoring system & No. of studies \\
\hline AOFAS Ankle/Hindfoot scale & 16 \\
Scoring system developed by the authors & 18 \\
Hannover score & 5 \\
Patient satisfaction score & 5 \\
Criteria proposed by Berndt and Harty & 5 \\
Visual analog scale & 3 \\
Martin score & 3 \\
Alexander and Lichtman & 3 \\
Ogilvie Harris score & 2 \\
MODEMS & 2 \\
Karlsson scoring scale & 2 \\
Tegner score & 1 \\
Evaluation proposed by Loomer & 1 \\
Mazur score & 1 \\
Freiburg ankle score & 1 \\
SANE & 1 \\
According to Thompson and Loomer & 1 \\
McCullough score & 1 \\
\hline
\end{tabular}

Some studies used more than one scoring system 
the past (1953 [45] and 1975 [7]), when surgical treatment of osteochondral talar lesions was not as common as it is today. In the majority of studies, the duration of symptoms prior to institution of non-operative treatment was either unreported or ranged from sub-acute to acute ( $<6$ weeks) to chronic ( $>6$ weeks). In the most recent study, patients were given the choice between operative and non-operative treatments, and the patient chose non-operative treatment. Conservative treatment consisted of weightbearing as tolerated [51]. In 39 of 86 patients (45\%), conservative treatment reported to be successful (range 20-54\%).

\section{Non-operative treatment: cast}

The aim is similar to the treatment option described previously, but then pursued by cast immobilization for at least 3 weeks up to 4 months. Four studies reported the results of this treatment $[7,10,22,41]$. All date back at least two decades. The main reason to decide for cast immobilization was a Berndt and Harty stage II or III lesion. In 44 of the 83 patients $(53 \%)$, the treatment was reported to be successful (range 29-69\%).

\section{Excision}

The partially detached fragment is excised, and the defect itself is left untreated. The results were reported in four studies [12, 23, 37, 41]. In two studies, excision was performed for superficial cartilaginous lesions, with mainly intact underlying subchondral bone. Sometimes it involved a loose intra-articular fragment. In one study, the lesions involved bony necrosis underneath. In 32 of 59 patients, the result was reported to be successful (54\%). Success rates varied from 30 to $88 \%$.

\section{Excision and curettage}

After excision of the loose body, the surrounding necrotic subchondral tissue is curetted using either an open or arthroscopic technique. Most patients had a Berndt and Harty stage III or IV lesion, although also stage II lesions occurred. Thirteen studies, a total of 259 patients, reported the results of OCD treatment by excision and curettage [7, $10,12,17,22,23,32,33,35,38,39,42,44]$. In 199 of 259 patients, a successful result was reported (77\%). The success rate varied from 56 to $94 \%$.

\section{Excision, curettage and BMS}

Following excision and curettage (debridement), multiple connections with the subchondral bone are created. This can be accomplished by drilling or microfracturing. The objective is to partially destroy the calcified zone that is most often present and to create multiple openings into the subchondral bone. Intra-osseous blood vessels are disrupted, and the release of growth factors leads to the formation of a fibrin clot. The formation of local new blood vessels is stimulated, bone marrow cells are introduced in the osteochondral defect, and fibro-cartilaginous tissue is formed. Patients often had a Berndt and Harty stage III or IV lesion, although stage I and II lesions occurred. Diameter of the lesions usually did not exceed $1.5 \mathrm{~cm}$. A total of 18 studies, including 388 patients, described the results of BMS [2, 3, 5, 8, 11, 13, $14,17-19,21,34,36,37,48,52,55,60]$. In 329 of 386 patients, treatment was reported to be successful $(85 \%)$. The success rate varied from 46 to $100 \%$.

\section{Excision, curettage and autogenous bone graft}

In this technique, the defect that remains after excision, and curettage is filled with autogenous cancellous bone. The aim is to restore the weightbearing properties of the talus. Indications for treatment were large, often medial lesions, exceeding $1.5 \mathrm{~cm}$ in diameter. Four publications reported the results of this technique for 74 patients [9, 13, 25, 27]. In 45 of 74 patients, the result was successful. Success rates varied from 41 to $93 \%$.

\section{Antegrade (transmalleolar) drilling}

In case an osteochondral lesion is hard to reach because of its location on the talar dome, the defect can be drilled through the malleolus. A K-wire is inserted about $3 \mathrm{~cm}$ proximal to the tip of the medial malleolus and directed across the medial malleolus into the lesion through the intact cartilage. Two publications described the results of this technique for 41 patients [26, 44]. In 26 patients, the result was reported to be successful (63\%, range 32-100\%).

\section{Osteochondral transplantation/OATS}

Osteochondral autografts have been introduced as an alternative to allografts for the treatment of OCDs. Two related procedures have been developed: mosaicplasty and OATS. Both are reconstructive bone grafting techniques that use one or more cylindrical osteochondral grafts from the less weightbearing periphery of the ipsilateral knee and transplant them into the prepared defect site on the talus. Its goal is to reproduce the mechanical, structural and biochemical properties of the original hyaline articular cartilage which has become damaged. It is carried out either by an open approach or by an arthroscopic procedure. Indications involve large, often medial lesions, sometimes with a cyst underneath. In some cases, it involves secondary treatment, after failed primary (surgical) treatment. Nine publications described the results of 243 patients treated by osteochondral 
transplantation $[1,15,17,20,28,31,47,49,50]$. Good/ excellent results were obtained in 212 patients $(87 \%)$. Success rates varied from 74 to $100 \%$. Morbidity of the donor knee joint was seen in $12 \%$ of patients $(0-37 \%)$. Three studies did not discuss the possibility of post-operative knee pain $[20,28,47]$.

\section{Autologous chondrocyte implantation/ACI}

Autologous chondrocyte implantation attempts to regenerate tissue with a high percentage of hyaline-like cartilage. By means of an arthroscopic approach, a region of healthy articular cartilage is identified, and a biopsy is taken. The tissue is minced and enzymatically digested. Chondrocytes are separated by filtration, and the isolated chondrocytes are cultivated in culture medium for 11-21 days. An arthrotomy is performed, and the chondral lesion is excised up to the healthy surrounding cartilage. A periosteal flap is removed from the tibia and is sutured to the surrounding rim of normal cartilage. The cultured chondrocytes are then injected beneath the periosteal flap. It is done for lesions larger than $1 \mathrm{~cm}^{2}$, in the absence of generalized osteoarthritic changes. Four studies, describing 59 patients, were included $[4,16$, $40,63]$. In 45 of 59 patients $(76 \%)$, a successful result was reported. The success rate varied from 70 to $92 \%$.

\section{Retrograde drilling}

Retrograde drilling is done for primary OCDs when there is more or less intact cartilage with a large subchondral cyst, or when the defect is hard to reach via the usual anterolateral and anteromedial portals. For medial lesions, arthroscopic drilling can take place through the sinus tarsi. For lateral lesions the cyst is approached from anteromedial. The aim is to induce subchondral bone revascularization and subsequently to stimulate the formation of new bone. A cancellous graft may be placed to fill the gap. Three studies, comprising 42 patients, were included [26, $46,53]$. It mainly involved medial lesions. Size of the lesions was not described. Post-operatively immediate range-of-motion exercises were commenced in all studies. Partial weightbearing was started 2,4 or 6 weeks postoperatively [26, 46, 53]. In 37 of 42 patients, the treatment was reported to be successful (88\%, range $81-100 \%)$.

\section{Fixation}

In case of a large loose fragment, one can choose to secure it to the underlying bone using either a screw, pin, rod or fibrin glue. One publication, for a total of 27 patients, met our inclusion criteria [29]. In this study, stage II-IV lesions were elevated, the bed was curetted and drilled, and after alignment of the fragment it was reattached with at least two bone pegs from the distal tibia. Results were reported to be successful in 24 patients (89\%).

Results are summarized in Table 3.

Quality assessment of included studies

On 'study design', together 52 studies scored a total of 28 stars, out of a possible 104. Seven studies were prospective in design; however, most case series were retrospectively

Table 3 Results per treatment strategy

\begin{tabular}{|c|c|c|c|c|c|}
\hline Treatment strategy & No. of studies & No. of patients & $\begin{array}{l}\text { No. of patients } \\
\text { good/excellent result }\end{array}$ & $\begin{array}{l}\text { Study weighted } \\
\text { success rate }(\%)\end{array}$ & Range $(\%)$ \\
\hline Non-operative, rest & 3 & 86 & 39 & 45 & $20-54$ \\
\hline Non-operative, cast & 4 & 83 & 44 & 53 & $29-69$ \\
\hline Excision & 4 & 59 & 32 & 54 & $30-88$ \\
\hline Excision and curettage & 13 & 259 & 199 & 77 & $56-94$ \\
\hline Excision, curettage and BMS & 18 & 388 & 329 & 85 & $46-100$ \\
\hline Autogenous bone graft & 4 & 74 & 45 & 61 & $41-93$ \\
\hline TMD & 2 & 41 & 26 & 63 & $32-100$ \\
\hline OATS & 9 & 243 & 212 & 87 & $74-100$ \\
\hline ACI & 4 & 59 & 45 & 76 & $70-92$ \\
\hline Retrograde drilling & 3 & 42 & 37 & 88 & $81-100$ \\
\hline Fixation, bone pegs & 1 & 27 & 24 & 89 & - \\
\hline
\end{tabular}

Described are the number of included studies per treatment strategy as mentioned in the first column, the cumulative number of patients per treatment strategy, the number of patients with a good or excellent result at follow-up, the success percentage per treatment strategy and finally the range of the success percentages

$B M S$ bone marrow stimulation, $A C I$ autologous chondrocyte implantation, OATS osteochondral autograft transfer system, TMD transmalleolar drilling 
executed [36], and in 9 studies, the pro- or retrospective nature of the study was not described. Twenty-one studies accounted for the protocol they had followed, but the majority of studies did not mention a protocol, or did not describe it properly. On 'selection,' 48 out of 52 possible stars were scored. Nearly all studies reported on a representative patient group. On 'outcome' 34 out of 104 stars were scored. In none of the studies, blind assessment was described (often it was not clear whether patients were scored by someone else than the author), and loss to follow up exceeded $5 \%$ in many cases.

\section{Discussion}

The most important finding of the present study was that bone marrow stimulation (BMS) was identified as the best treatment option.

The review summarizes 65 study groups in 52 studies that describe treatment strategies for osteochondral talar lesions. There was a great diversity in trials concerning patient characteristics, staging of the defect, duration of follow-up and outcome measures. A relatively large number of studies were dedicated to treatment by excision and curettage, excision and curettage and BMS, and OATS. The number of patients in other categories, mainly retrograde drilling, fixation and transmalleolar drilling (TMD), was too limited for a reliable interpretation of the results. Therefore, no definitive conclusions can be drawn. Recommendations concerning these techniques must be judged in this light. Retrograde drilling is usually reserved for large OCDs with intact overlying cartilage, as confirmed by arthroscopy. It is the treatment of choice when there is a large subchondral cyst with overlying healthy cartilage. However, sizes of the lesions were not described in any of the studies concerning retrograde drilling [26, 46, 53]. Fixation is indicated for lesions in which a large fragment can be reattached. It is applied especially in (sub)acute cases and in adolescents and children. Transmalleolar drilling is performed when a defect is hard to reach because of its location on the talar surface. A disadvantage is that healthy tibial cartilage is damaged. The reported results do not support the use of this technique [26, 44]. Besides, most talar lesions can be reached by means of the standard anterior or posterior arthroscopic approach, using intermittent distraction and a $90^{\circ}$ microfracture probe $[58,59,64]$.

The results of non-operative treatment were low compared to operative treatment. In spite of this, non-operative treatment should always be the first treatment to be considered.

Today, most publications on treatment of osteochondral lesions of the talus involve arthroscopic excision, curettage and bone marrow stimulation, ACI and OATS. They scored success percentages of 85,76 and 87 , respectively. ACI is a relatively expensive technique, and OATS gives morbidity from knee complaints in a relevant number of patients-up to $36 \%$ in literature $[1,15,30,43]$. Therefore, we recommend arthroscopic excision, curettage and BMS to be the first treatment of choice for primary osteochondral talar lesions. It is relatively inexpensive, there is low morbidity, a quick recovery and a high success rate.

The results of this review differ slightly from the results described in the review of Verhagen et al. [61]. Results of both reviews are listed in Table 4 . The success percentage for BMS has changed very little. Verhagen included 21 studies and 227 patients, and this review included 18 studies and 388 patients. The success rate went from 86 to $85 \%$. For OATS, the success rate changed from 94 to $87 \%$. Verhagen found one study with 36 patients treated with this technique. We identified nine eligible studies comprising 243 patients.
Table 4 Success percentages (patients with a good/excellent result at follow-up after treatment of an osteochondral talar lesion) of a previous review by Verhagen et al. [61] compared to the current review

\begin{tabular}{lcl}
\hline Treatment strategy & $\begin{array}{l}\text { Verhagen et al. studies } \\
\text { published up to 2000 }(\%)\end{array}$ & $\begin{array}{l}\text { Current review, studies } \\
\text { published up to 2006 (\%) }\end{array}$ \\
\hline Non-operative treatment-rest & 45 & 45 \\
Non-operative treatment-cast & - & 53 \\
Excision & 38 & 54 \\
Excision and curettage & 76 & 77 \\
Excision, curettage and BMS & 86 & 85 \\
Autogenous bone graft & 85 & 61 \\
TMD & - & 63 \\
OATS & 94 & 87 \\
ACI & - & 76 \\
Retrograde drilling & 81 & 88 \\
Fixation & 73 & 89 \\
Total & & 76 \\
\hline
\end{tabular}


In the previous review, the ACI technique was not included. We now identified four studies, comprising 59 patients, describing the results of ACI, leading to a success percentage of $76 \%$. Our exclusion criteria were stricter than those of the previous review. Considering the number of patients, Verhagen et al. excluded single case reports, but included series of two patients and more. To be included in our review, each study group had to involve 10 patients or more. This excluded the 'extended case reports' and only allowed true case series to be evaluated. Our initial goal was to only include study groups of 20 patients or more. This protocol, however, excluded too many studies, and we stretched our criteria to 10 patients. In comparison with Tol [57], this eliminated 13 studies (and 18 treatment groups) and in comparison with Verhagen [61] it is 30 studies.

For the quality of the review, we would have preferred to include only the highest level of evidence, which are randomized clinical trials. However, only one RCT was identified, describing the results of chondroplasty (excision and curettage), microfracturing and osteochondral transplantation [17]. Looking at the set-up and inclusion of this study one, can debate whether this study was a truly randomized trial, as is also stated by the authors of the article. We identified no case control studies.

Assessment of quality by the adjusted NOS showed that studies scored low on study design. Studies scored moderately concerning 'outcome', since no study described whether blind assessment was part of the protocol, and in many studies there was a loss to follow up exceeding 5\%. The NOS adjusted for case series, as used in this study, has not been validated. However, scoring low on the items described earlier leads to a higher chance of introducing bias.

The clinical relevance of the present study is the identification of the most effective treatment options for primary osteochondral lesions of the talus, which can serve as a guideline for treatment in clinical practice.

\section{Conclusion}

Based on the current best available evidence, at present, treatment by means of debridement and bone marrow stimulation is the most effective treatment strategy for symptomatic osteochondral lesions of the talus. To draw definitive conclusions, sufficiently powered, randomized clinical trials with uniform methodology and validated outcome measures should be initiated.

Acknowledgments The authors would like to thank Dwight Oostwoud (DO) (Department of Emergency Medicine, OLVG, Amsterdam) for his supportive work in this study.
Open Access This article is distributed under the terms of the Creative Commons Attribution Noncommercial License which permits any noncommercial use, distribution, and reproduction in any medium, provided the original author(s) and source are credited.

\section{Appendix 1: Newcastle: Ottawa quality assessment scale}

Adjusted for case series

Study design

1. Type of study
a. Prospective*
b. Retrospective
c. Other
d. Not described

2. Set-up
a. According to protocol*
b. Without protocol
c. No protocol described

\section{Selection}

3. Representativeness of included patients
a. Truly representative of the average talar OCD patient in the community*
b. Somewhat representative of the average talar OCD patient in the community*
c. Selected group of patients by surgeon
d. No description of the derivation of the patient group

\section{Outcome}

4. Assessment of outcome
a. Independent blind assessment*
b. Record linkage*
c. Self-report
d. No description

5. Adequacy of follow-up of series
a. Complete follow-up-all subjects accounted for*
b. Subjects lost to follow-up unlikely to introduce bias-small number lost $(<5 \%)^{*}$
c. Follow-up rate $<95 \%$ and no description of those lost
d. No statement 
Number of assigned stars

\begin{tabular}{lll}
\hline Study design & Selection & Outcome \\
\hline
\end{tabular}

Every included study was separately assessed for quality using an adjusted version of the Newcastle Ottawa Scale, as described earlier. It was performed by scoring each study for study design (0-2 stars), selection of patients $(0-1$ star) and outcome (0-2 stars). The designs that earned a star are marked with a *. For each study, the total number of stars was noted in the box given

\section{References}

1. Al-Shaikh RA, Chou LB, Mann JA et al (2002) Autologous osteochondral grafting for talar cartilage defects. Foot Ankle Int 23:381-389

2. Alexander AH, Lichtman DM (1980) Surgical treatment of transchondral talar-dome fractures (osteochondritis dissecans). Long-term follow-up. J Bone Joint Surg Am 62:646-652

3. Baker CL Jr, Morales RW (1999) Arthroscopic treatment of transchondral talar dome fractures: a long-term follow-up study. Arthroscopy 15:197-202

4. Baums MH, Heidrich G, Schultz W et al (2006) Autologous chondrocyte transplantation for treating cartilage defects of the talus. J Bone Joint Surg Am 88:303-308

5. Becher C, Thermann H (2005) Results of microfracture in the treatment of articular cartilage defects of the talus. Foot Ankle Int 26:583-589

6. Berndt AL, Harty M (1959) Transchondral fractures (osteochondritis dissecans) of the talus. J Bone Joint Surg Am 41A:988-1020

7. Blom JM, Strijk SP (1975) Lesions of the trochlea tali. Osteochondral fractures and osteochondritis dissecans of the trochlea tali. Radiol Clin (Basel) 44:387-396

8. Bonnin M, Bouysset M (1999) Arthroscopy of the ankle: analysis of results and indications on a series of 75 cases. Foot Ankle Int 20:744-751

9. Bruns J (1993) Osteochondrosis dissecans tali. Results of surgical therapy. Unfallchirurg 96:75-81

10. Canale ST, Belding RH (1980) Osteochondral lesions of the talus. J Bone Joint Surg Am 62:97-102

11. Chin TW, Mitra AK, Lim GH et al (1996) Arthroscopic treatment of osteochondral lesion of the talus. Ann Acad Med Singap 25:236-240

12. Demaziere A, Ogilvie-Harris DJ (1991) Operative arthroscopy of the ankle. 107 cases. Rev Rhum Mal Osteoartic 58:93-97

13. Draper SD, Fallat LM (2000) Autogenous bone grafting for the treatment of talar dome lesions. J Foot Ankle Surg 39:15-23

14. Flick AB, Gould N (1985) Osteochondritis dissecans of the talus (transchondral fractures of the talus): review of the literature and new surgical approach for medial dome lesions. Foot Ankle 5:165-185

15. Gautier E, Kolker D, Jakob RP (2002) Treatment of cartilage defects of the talus by autologous osteochondral grafts. J Bone Joint Surg Br 84:237-244

16. Giannini S, Buda R, Grigolo B et al (2005) The detached osteochondral fragment as a source of cells for autologous chondrocyte implantation (ACI) in the ankle joint. Osteoarthr Cartil 13:601-607

17. Gobbi A, Francisco RA, Lubowitz JH et al (2006) Osteochondral lesions of the talus: randomized controlled trial comparing chondroplasty, microfracture, and osteochondral autograft transplantation. Arthroscopy 22:1085-1092

18. Guido G, Azzone S, Giannotti S (2005) Posttraumatic osteochondral lesions of the arthroscopically treated ankle. Chirurgia del Piede 29(2):61-66

19. Hakimzadeh A, Munzinger U (1979) Osteochondrosis dissecans: results after 10 or more years. c). Osteochondrosis dissecans of the ankle joint: long-term study. Orthopade 8:135-140

20. Hangody L, Fules P (2003) Autologous osteochondral mosaicplasty for the treatment of full-thickness defects of weight-bearing joints: ten years of experimental and clinical experience. J Bone Joint Surg Am 85-A(Suppl 2):25-32

21. Hunt SA, Sherman O (2003) Arthroscopic treatment of osteochondral lesions of the talus with correlation of outcome scoring systems. Arthroscopy 19:360-367

22. Huylebroek JF, Martens M, Simon JP (1985) Transchondral talar dome fracture. Arch Orthop Trauma Surg 104:238-241

23. Kelberine F, Frank A (1999) Arthroscopic treatment of osteochondral lesions of the talar dome: a retrospective study of 48 cases. Arthroscopy 15:77-84

24. Kitaoka HB, Alexander IJ, Adelaar RS et al (1994) Clinical rating systems for the ankle-hindfoot, midfoot, hallux, and lesser toes. Foot Ankle Int 15:349-353

25. Kolker D, Murray M, Wilson M (2004) Osteochondral defects of the talus treated with autologous bone grafting. J Bone Joint Surg $\mathrm{Br} 86: 521-526$

26. Kono M, Takao M, Naito K (2006) Retrograde drilling for osteochondral lesions of the talar dome. Am J Sports Med 34:1450-1456

27. Kouvalchouk JF, Schneider-Maunoury G, Rodineau J et al (1990) Osteochondral lesions of the dome of the talus with partial necrosis. Surgical treatment by curettage and filling. Rev Chir Orthop Reparatrice Appar Mot 76:480-489

28. Kreuz PC, Steinwachs M, Erggelet C et al (2006) Mosaicplasty with autogenous talar autograft for osteochondral lesions of the talus after failed primary arthroscopic management: a prospective study with a 4-year follow-up. Am J Sports Med 34:55-63

29. Kumai T, Takakura Y, Kitada C et al (2002) Fixation of osteochondral lesions of the talus using cortical bone pegs. J Bone Joint Surg Br 84:369-374

30. LaPrade RF, Botker JC (2004) Donor-site morbidity after osteochondral autograft transfer procedures. Arthroscopy 20:e69-e73

31. Lee CH, Chao KH, Huang GS et al (2003) Osteochondral autografts for osteochondritis dissecans of the talus. Foot Ankle Int 24:815-822

32. Lundeen RO, Stienstra JJ (1987) Arthroscopic treatment of transchondral lesions of the talar dome. J Am Podiatr Med Assoc 77:456-461

33. Martin DF, Baker CL, Curl WW et al (1989) Operative ankle arthroscopy. Long-term followup. Am J Sports Med 17:16-23

34. Mendicino RW, Lee MS, Grossman JP et al (1998) Oblique medial malleolar osteotomy for the management of talar dome lesions. J Foot Ankle Surg 37:516-523

35. Ming SH, Tay Keng Jin D, Amit Kanta M (2004) Arthroscopic treatment of osteochondritis dissecans of the talus. Foot Ankle Surg 10:181-186

36. Munoz M, Aznar P, Utrilla L (2002) Lesiones osteocondrales mediales de astrágalo. Valoración del abordaje quirúrgico transmaleolar. Rev Ortop Traumatol 46:510-514

37. O'Farrell TA, Costello BG (1982) Osteochondritis dissecans of the talus. The late results of surgical treatment. J Bone Joint Surg Br 64:494-497

38. Ogilvie-Harris DJ, Sarrosa EA (1999) Arthroscopic treatment of osteochondritis dissecans of the talus. Arthroscopy 15:805-808

39. Parisien JS (1986) Arthroscopic treatment of osteochondral lesions of the talus. Am J Sports Med 14:211-217 
40. Petersen L, Brittberg M, Lindahl A (2003) Autologous chondrocyte transplantation of the ankle. Foot Ankle Clin 8:291-303

41. Pettine KA, Morrey BF (1987) Osteochondral fractures of the talus. A long-term follow-up. J Bone Joint Surg Br 69:89-92

42. Pritsch M, Horoshovski H, Farine I (1986) Arthroscopic treatment of osteochondral lesions of the talus. J Bone Joint Surg Am 68:862-865

43. Reddy S, Pedowitz DI, Parekh SG et al (2007) The morbidity associated with osteochondral harvest from asymptomatic knees for the treatment of osteochondral lesions of the talus. Am J Sports Med 35:80-85

44. Robinson DE, Winson IG, Harries WJ (2003) Arthroscopic treatment of osteochondral lesions of the talus. J Bone Joint Surg Br 85:989-993

45. Röden S, Tillegard P, Unander-Scharin L (1953) Osteochondritis dissecans and similar lesions of the talus. Report of fifty-five cases with special reference to etiology and treatment. Acta Orthop Scand 23:51-66

46. Rosenberger RE, Fink C, Bale RJ et al (2006) Computer-assisted minimally invasive treatment of osteochondrosis dissecans of the talus. Oper Orthop Traumatol 18:300-316

47. Sammarco GJ, Makwana NK (2002) Treatment of talar osteochondral lesions using local osteochondral graft. Foot Ankle Int 23:693-698

48. Schuman L, Struijs PA, van Dijk CN (2002) Arthroscopic treatment for osteochondral defects of the talus. Results at follow-up at 2 to 11 years. J Bone Joint Surg Br 84:364-368

49. Scranton PE Jr, Frey CC, Feder KS (2006) Outcome of osteochondral autograft transplantation for type- $\mathrm{V}$ cystic osteochondral lesions of the talus. J Bone Joint Surg Br 88:614-619

50. Scranton PE Jr, McDermott JE (2001) Treatment of type V osteochondral lesions of the talus with ipsilateral knee osteochondral autografts. Foot Ankle Int 22:380-384

51. Shearer C, Loomer R, Clement D (2002) Nonoperatively managed stage 5 osteochondral talar lesions. Foot Ankle Int 23:651654

52. Takao M, Uchio Y, Kakimaru H et al (2004) Arthroscopic drilling with debridement of remaining cartilage for osteochondral lesions of the talar dome in unstable ankles. Am J Sports Med $32: 332-336$
53. Taranow WS, Bisignani GA, Towers JD et al (1999) Retrograde drilling of osteochondral lesions of the medial talar dome. Foot Ankle Int 20:474-480

54. Thermann H (1994) Treatment of osteochondritis dissecans of the talus: a long term follow-up. Sports Med Arthrosc Rev 284-288

55. Thermann H, Becher C (2004) Microfracture technique for treatment of osteochondral and degenerative chondral lesions of the talus. 2-year results of a prospective study. Unfallchirurg 107:27-32

56. Thompson JP, Loomer RL (1984) Osteochondral lesions of the talus in a sports medicine clinic. A new radiographic technique and surgical approach. Am J Sports Med 12:460-463

57. Tol JL, Struijs PA, Bossuyt PM et al (2000) Treatment strategies in osteochondral defects of the talar dome: a systematic review. Foot Ankle Int 21:119-126

58. van Dijk CN (2006) Hindfoot endoscopy for posterior ankle pain. Instr Course Lect 55:545-554

59. van Dijk CN, Verhagen RA, Tol HJ (2001) Technical note: resterilizable noninvasive ankle distraction device. Arthroscopy 17:E12

60. Van BK, Barrack RL, Alexander AH et al (1989) Arthroscopic treatment of transchondral talar dome fractures. Am J Sports Med $17: 350-355$

61. Verhagen RA, Struijs PA, Bossuyt PM et al (2003) Systematic review of treatment strategies for osteochondral defects of the talar dome. Foot Ankle Clin 8:233-242

62. Wells G, Shea B, O'Connell D (2000) The Newcastle-Ottawa Scale for assessing the quality of nonrandomized studies in metaanalyses. Oxford. Proceedings of the 3rd Symposium on Systematic Reviews. Beyond the basics: improving quality and impact. http://www.ohri.ca/programs/clinical_epidemiology/oxford.htm

63. Whittaker JP, Smith G, Makwana N et al (2005) Early results of autologous chondrocyte implantation in the talus. J Bone Joint Surg Br 87:179-183

64. Zengerink M, Szerb I, Hangody L et al (2006) Current concepts: treatment of osteochondral ankle defects. Foot Ankle Clin $11: 331-359$ 